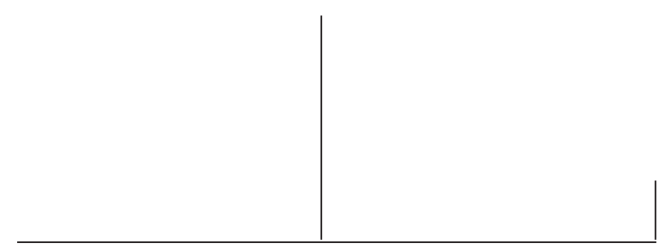

Rev. Latinoam. Psicopat. Fund., IV, 2, 29-40

\title{
Diagnóstico, psicopatologia e psicanálise de orientação lacaniana*
}

\author{
Márcio Peter de Souza Leite
}

Para abordar a questão do diagnóstico em psicopatologia na psicanálise de orientação lacaniana, o autor primeiro questiona a existência de uma psicopatologia psicanalitica, bem como a existência de uma especificidade para o diagnóstico psicanalítico.

Desenvolve depois a noção de envoltório formal do sintoma e de posição subjetiva como os eixos que orientam o diagnóstico na psicanálise lacaniana.

A partir daí o autor aponta a existência de dois modelos clínicos em Lacan, o que impõe dois modelos diagnósticos: um primeiro, a clínica estrutural, e um segundo, a clínica borromeana.

A clínica estrutural seria descontinuista e categorial e estaria fundada sobre a modalidade da oposição orientando-se em função da oposição da existência e não existência da função paterna. Esta clínica é tripartida entre neurose, psicose e perversão.

A clínica borromeana tem a caraterística de não se referir às categorias nosológicas da psiquiatria clássica e funda-se na relação dos registros do Imaginário, do Simbólico e do Real, segundo as propriedades de figura topológica do nó Borromeano. Ela é uma clinica continuista e não categorial.

Palavras-chave: Diagnóstico, psicopatologia, clínica estrutural, clínica borromeana

* Texto apresentado no IV Congresso do Laboratório de Psicopatologia Fundamental em setembro de 2000, Campinas, SP. 


\section{Existe uma psicopatologia psicanalítica?}

Sobre o tema diagnóstico em psicopatologia, existem duas questões que, dentro de uma perspectiva psicanalítica, são pré-requisitos para este estudo.

A primeira questão: existe uma psicopatologia psicanalítica? A segunda: há uma especificidade do diagnóstico feito em psicanálise?

Para responder a estas perguntas, deve-se levar em conta os diferentes usos e abordagens empregados à palavra psicopatologia e à palavra diagnóstico. Para depois situar, na psicanálise de orientação lacaniana, o uso específico que se faz destes termos.

Quanto ao termo psicopatologia, Dalgalarrondo (2000: 28-30) apud Campbell define-o da seguinte maneira: “... ramo da ciência que trata da natureza essencial da doença mental, suas causas, as mudanças estruturais e funcionais associadas a ela e suas formas de manifestação". Definição que, como se pode notar, está relacionada à tradição médica, fundada na observação da doença mental.

Contrapondo-se a esta definição, existem outras, como é o caso da que foi dada por Jaspers que, por sua vez, considera a psicopatologia como uma ciência autônoma, independente da medicina ou da psicologia. Porém, fazendo uso da tradição humanista, este autor acabou incluindo a filosofia na formulação da psicopatologia.

Tendo em vista a presença de uma grande disparidade teórica na abordagem da psicopatologia, Fédida (1998: 107-121), em uma visão mais atual, considera a psicopatologia como uma encruzilhada epistemológica na qual juntam-se disciplinas científicas heterogêneas que têm em comum a preocupação pelo sofrimento psíquico.

As múltiplas definições de psicopatologia mostram que não há um consenso neste campo. Dito de outra forma: a existência de muitas e diferentes escolas revela a permanência da multiplicidade de abordagens e referências teóricas que a psicopatologia tem incorporado nos dois últimos séculos. 


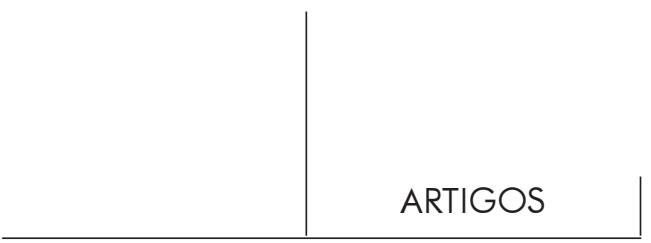

Por isso, é de interesse a ordenação do campo da psicopatologia que está no livro de Dalgalarrondo, onde há uma proposta de sistematização da psicopatologia feita através do delineamento de oposições. Delineamento que, em primeiro lugar, faz o autor contrapor uma psicopatologia Descritiva e uma psicopatologia Dinâmica. Sendo que a primeira se caracterizaria por privilegiar a forma do sintoma e a segunda por privilegiar o conteúdo do sintoma.

Em segundo lugar, o autor opõe uma psicopatologia Médica - caracterizada por considerar a psicopatologia como conseqüência do mau funcionamento do cérebro - a uma psicopatologia Existencial - caracterizada por entender o doente como uma existência singular.

Em terceiro, opõe uma psicopatologia Comportamental - que entende o homem como um conjunto de comportamentos observáveis - a uma psicopatologia Psicanalítica - que entende o homem como determinado por desejos e conflitos inconscientes.

Haveria também uma psicopatologia Categorial que concebe os transtornos mentais como espécies únicas, ou seja, como entidades ou categorias diagnósticas diferentes e discerníveis na sua natureza básica. A Categorial opõe-se à psicopatologia Dimensional que propõe uma visão dimensional em psicopatologia, isto é, inclui gradações nos quadros clínicos.

Haveria ainda uma psicopatologia Biológica - que enfatiza os aspectos neurofisiológicos dos sintomas mentais - e que seria oposta a uma psicopatologia Sociocultural que entende os transtornos mentais como comportamentos desviantes. Comportamentos, estes, que surgiriam a partir de determinados fatores socioculturais, simbólicos e históricos.

Finalmente, uma psicopatologia denominada de Operacional-pragmática - que não questiona a natureza da doença (ou dos sintomas) e que serve de modelo para o DSM e para o CID - opor-se-ia a uma psicopatologia Fundamental que centra a atenção da pesquisa sobre o fundamento de cada conceito psicopatológico.

Quanto ao uso do termo diagnóstico, admite-se que ele esteja ligado à idéia de reconhecimento. Na medicina, sua significação é o "reconhecimento de uma doença". O diagnóstico seria um instrumento cognitivo com finalidade de reconhecer um objeto, acontecimento ou estrutura, através de suas características ou signos evidentes.

Um diagnóstico pode ser descritivo ou explicativo. Daí sua definição clássica em medicina como conhecimento obtido por meio da observação de certos signos que, por isto mesmo, são chamados de signos diagnósticos.

Saurí (1994) faz um estudo exaustivo da problemática do diagnóstico, esclarecendo o que é um diagnóstico e resumindo suas idéias com os seguintes aforismos:

Primeiro: diagnosticar é agrupar signos.

Segundo: diagnosticar é situar o comprovado em um esquema transcendental. 


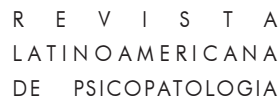

Terceiro: diagnosticar é detectar o desenvolvimento das organizações (inconscientes).

Quarto: diagnosticar é uma atividade axiomática.

Em seguida, entrando no tema de como se faz o diagnóstico, o autor sugere três momentos: um primeiro que é chamado de constitutivo. Um segundo que é o operativo. E um terceiro que é o temporal.

Finalmente, referindo-se ao ordenamento diagnóstico, conclui que as categorias diagnósticas seriam conjuntos signicos justificados como aspectos manifestos das figuras clínicas. Questão que, tendo em vista a natureza do acontecimento psicopatológico, faz diferir o diagnóstico psicopatológico do diagnóstico médico, tanto em relação ao objeto quanto em relação às suas funções e objetivos.

O diagnóstico em psicopatologia tem um caráter gnosológico, ou seja, além de ser uma categoria de conhecimento, ele também é um instrumento de comunicação e de previsão.

Para abordar o tema do diagnóstico em psicopatologia, a partir da psicanálise, deve-se responder se existe uma psicopatologia psicanalítica, o que está feito em um texto escrito por Fédida e Lacoste. (1998: 23-57)

Para este autores, sem dúvida, existe uma psicopatologia freudiana. Contudo, eles afirmam que isto não está evidente na obra de Freud e, assim, sugerem a busca da psicopatologia freudiana na metapsicologia.

Para Fédida e Lacoste ainda não se avaliou suficientemente a incidência da metapsicologia sob a psicopatologia. Por isso, a sugestão é de que se conceba a metapsicologia como uma perspectiva da psicopatologia que tem a característica de definir seu objeto, indicando a posição do sujeito que observa.

Também seria importante mencionar a crítica feita por Fédida a uma psicopatologia centrada na condição fenomenológica, e lembrar sua proposta de subverter este modelo, através de uma psicopatologia chamada de fundamental.

Desde este ponto de vista, a psicanálise se aproximaria mais da psicopatologia fundamental do que da geral. Isto devido aos deslocamentos que a psicanálise fez em relação à noção de normalidade, devido às transformações que produziu nos modelos teóricos e também devido à preservação que ela fez do particular da história de cada sujeito no entendimento da causação do sintoma.

\section{Existe um diagnóstico psicanalítico?}

Quanto a segunda questão - se existe uma especificidade do diagnóstico feito em psicanálise - deve-se levar em conta que, ao clínico, se impõe que um diagnóstico é sempre produto de uma combinatória destes signos. Assim como, considerando a existência de um grande número de escolas de psicopatologia que fazem 


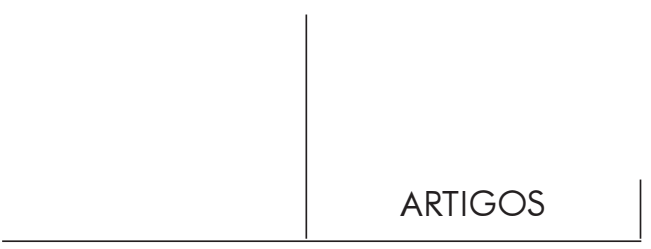

uso da terminologia psicopatológica de forma discordante, deve-se lembrar que a combinatória de signos, que determina um diagnóstico, é sempre efeito do referencial em uso.

Disto decorre que as categorias diagnósticas só podem ser entendidas como convenções de caráter pragmático, ou seja, as categorias diagnósticas só podem ser entendidas como efeitos do que se chamou de razão classificatória.

Por isto, ao utilizar qualquer critério classificatório de diagnósticos, o psicanalista não foge do que o antropólogo Lévi-Strauss sugeriu como sendo o princípio lógico da epistemologia das classificações. Princípio este que, no caso, se refere à produção constante de termos opostos; o que, por sua vez, rege e garante as classificações.

Dentro desta perspectiva, toda classificação pode ser entendida como sendo o resultado da análise e da comparação por seriação, com a finalidade de facilitar e promover o conhecimento.

Deste modo, uma classificação sempre implica em uma nomenclatura, que é o conjunto dos termos particulares de uma arte ou ciência. O que, no caso da medicina, é conhecido por nosologia (o estudo das doenças) e por nosografia (a descrição das doenças).

Então, qual seria o referencial que a psicanálise usa na elaboração de seus diagnósticos? Freud usou como referencial a nosografia da psiquiatria clássica, tomando dela suas categorias diagnósticas.

Por exemplo, Freud - contemporâneo de Krafft-Ebing - tomou deste autor o termo Perversão, assim como utilizou, segundo Kraepelin, o diagnóstico de Paranóia. Por outro lado, não aceitou a inovação feita por Bleuler em relação à Esquizofrenia e retirou a noção de Neurose de Charcot.

Mas, mesmo referindo-se sistematicamente às categorias psicopatológicas da psiquiatria da época, Freud produziu uma nomenclatura própria da psicanálise, com isso, fazendo uma ruptura com a nomenclatura psiquiátrica. Ou seja, ao mesmo tempo, Freud conseguiu manter e subverter a nomenclatura dada. Exemplo disto foi a invenção de categorias diagnósticas inexistentes na clínica psiquiátrica de seu tempo, tal como a introdução dos termos neurose de angústia e neurose atual. Também foi subversiva a proposta de ordenar entre si os quadros clínicos das neuroses com o conceito de psiconeurose. Ainda se poderia apontar a neurose de transferência e a neurose narcísica como sendo inovações introduzidas por Freud.

A nosologia e nosografia freudianas influenciaram a psiquiatria em suas classificações até o CID-9. Já o CID-10 (1998) marcou justamente um abandono do modelo freudiano ao separar a unidade freudiana das neuroses em entidades separadas, tais como: o transtorno de ansiedade, os quadros dissociativos, o TOC etc. 


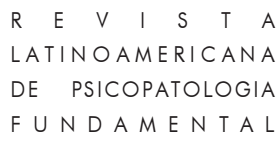

Diagnóstico, envoltório formal do sintoma e posição do sujeito

E qual a posição da psicanálise de orientação lacaniana frente às categorias diagnósticas?

Lacan, no texto De nossos antecedentes (1998: 69-78), ao afirmar que a origem de seu pensamento reside no rastro de Clérambault (seu único mestre em psiquiatria), diz que o automatismo mental "com sua ideologia mecanicista de metáfora nos parece em sua maneira de abordar o texto subjetivo, o mais próximo que pode constituir-se por uma análise estrutural".

Quer dizer que, para Lacan, a evidência clínica a se classificar continuou a ser verificada no fenômeno. No entanto, ao criticar a noção Jasperiana de compreensão, Lacan esforçou-se para situar no sujeito a pertinência do fenômeno. Ou melhor, pretendeu demonstrar a relação do fenômeno com a sua determinação causal.

Em função disto, Lacan criou a expressão "envoltório formal do sintoma" que serve para indicar que, no sintoma, nem tudo é significante.

Lacan (1998a), referindo-se à clínica psicanalítica, diz: "Existem tipos de sintomas, existe uma clínica. Só que ela é anterior ao discurso analítico (...)”.

A afirmação de Lacan de que "existem tipos de sintomas" implica que, na referência a tipos diferentes de sintomas, existe uma descrição de fenômenos que seriam observáveis fora da transferência. Isto é, a nomeação e classificação destes fenômenos estariam relacionadas às categorias descritas antes da descoberta da psicanálise.

O psicanalista de orientação lacaniana, sem dúvida, concorda com a existência de diferentes tipos de sintomas. Foi disto que Lacan tratou ao relacionar o universal dos diversos tipos de sintomas com o particular de cada sujeito, através da idéia de um "envoltório formal do sintoma".

Dito de outra forma, a idéia de um envoltório formal do sintoma é uma resposta ao ordenamento dos sintomas, antes feito pela clínica psiquiátrica e, depois, abordados pela teoria do significante.

Em compensação, logo após referir-se à existência dos diferentes tipos clínicos, Lacan acrescenta: “... que os tipos clínicos resultem da estrutura, eis o que já se pode escrever, ainda que não sem hesitação (...)”. (Ibid.)

Ou seja, por um lado, Lacan não mudou (nem poderia mudar) as categorias descritivas da psiquiatria clássica. Mas, por outro lado, ao tentar construir as estruturas que condicionariam estes diversos tipos de sintomas, Lacan inevitavelmente avançou.

Por isto, as entrevistas preliminares se apresentam como um meio do analista investigar estes tipos de sintomas, permitindo fazer um diagnóstico preliminar que possa concluir algo sobre a estrutura clínica da pessoa que veio consultá-lo. 


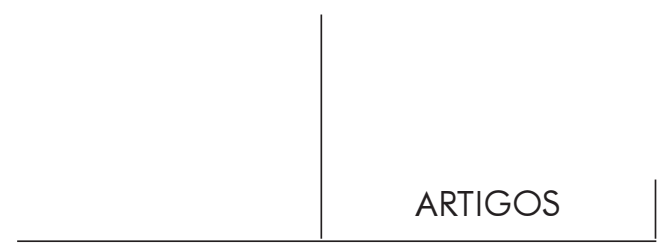

Por sua vez, esta estrutura é evidenciada a partir da defesa que o sujeito apresenta frente à angústia. Assim, a divisão diagnóstica (neurose, psicose e perversão) é feita em função da diferença dos efeitos produzidos pelo tipo de defesa próprio de cada uma destas estruturas.

Deste modo, para diagnosticar, por exemplo, uma estrutura perversa, não basta ao analista somente perguntar ao paciente sobre a sua vida sexual. Afinal, o que define o diagnóstico em psicanálise não é a conduta. O que define o diagnóstico em psicanálise é a posição subjetiva frente ao sintoma, o que faz com que o diagnóstico em psicanálise não possa vir separado da localização subjetiva.

Melhor dizendo, na experiência analítica não se deve relevar apenas o tipo de sintoma que o analisante apresenta, mas, sobretudo, a posição que o analisante assume frente ao seu sintoma. O que é feito a partir do dizer, e não dos ditos.

Portanto, na psicanálise - diferentemente do diagnóstico feito na psiquiatria trata-se de distinguir entre o dito e uma posição frente ao dito. Sendo que o sujeito é justamente esta posição frente ao dito.

Levar em consideração a posição do sujeito frente ao sintoma (e não somente o tipo de sintoma), talvez seja o ponto que permita que a clínica psiquiátrica seja esclarecida pelo discurso psicanalítico. Desta maneira, a psicanálise poderia estar produzindo uma clínica nova que não dependa mais da psiquiatria.

Indo nessa direção: a especificidade de uma clínica psicanalítica (independente da psiquiatria) se deveria ao fato dela não situar o diagnóstico no sintoma, mas sim onde, nesse sintoma, se implica uma fantasia que o determina.

Desta maneira, a psicanálise de orientação lacaniana estaria deslocando uma clínica centrada unicamente nas formas do sintoma para uma outra clínica que, no caso, privilegia as modalidades da posição do sujeito na fantasia.

\section{Clínica estrutural e clínica borromeana}

Porém, esta maneira de entender o diagnóstico não abrange todo o ensino de Lacan. Na articulação da psicopatologia com o diagnóstico, uma clínica então seria uma prática que faz uso de uma determinada concepção do aparelho psíquico e que, desta concepção, deduz uma convenção diagnóstica.

Dentro desta perspectiva, os diagnósticos feitos na psicanálise de orientação lacaniana indicam, no momento atual, a existência de dois modelos: um primeiro, chamado de estrutural, no qual a referência principal é o envoltório formal do sintoma. Modelo que, portanto, refere-se às categorias da psicopatologia psiquiátrica e, dentro delas, privilegia o eixo psico-neurose. E um segundo modelo, chamado de clínica borromeana, que tem por característica a não-referência às categorias nosológicas da psicopatologia psiquiátrica. 
Resumindo: atualmente, na psicanálise de orientação lacaniana, pode-se identificar dois usos diferentes para o que se chama de clínica: a clínica estrutural e a clínica borromeana.

Em Lacan, a clínica que se convencionou como estruturalista tem como essência a distinção, a oposição e a diferença (Miller, 1998: 191-202). Esta clínica seria a que se encontra fundada sob a modalidade da oposição. Oposição que, no caso, é tripartida em neurose, perversão e psicose.

A rigor, a neurose e a perversão ficam do mesmo lado em relação à existência da função paterna. Assim, na psicanálise de orientação lacaniana, a oposição estrutural que ordena o campo da psicopatologia e do diagnóstico refere-se à oposição entre neurose e psicose.

Ou seja, a clínica estrutural, proposta pela orientação lacaniana, ordena-se em função da oposição entre a existência e a não-existência da função paterna. Sendo que o primeiro caso diz respeito à neurose, e o segundo à psicose.

Por isso, a clínica que se refere a este momento do ensino de Lacan é descontinuísta e categorial.

Não se pode negar que, dentro de um critério estruturalista, todas as classificações são apenas semblantes.

No entanto, a psicanálise de orientação lacaniana não é estanque porque Lacan foi sensível ao fato de que toda classificação deve comportar a classe dos inclassificáveis.

Esta outra maneira de pensar a clínica, chamada borromeana, se funda no fato do ser falante ser consequiência da relação entre Imaginário, Simbólico e Real. Relação que se dá segundo as propriedades de uma figura topológica, chamada nó borromeano.

O nó borromeano é um esforço para se pensar a estrutura (o Simbólico) fora de uma referência ao Outro. O objetivo de Lacan consiste em juntar o Uno - o gozo - a partir dos registros: R, S e I, enquanto fundamentalmente heterogêneos.

Dentro desta perspectiva, por algum motivo pode não haver amarração adequada entre os registros do R, do S e do I, o que constituiria um lapso do nó. Por outro lado, mesmo havendo amarração, existiria a possibilidade deste não ser borromeano.

Outra perspectiva introduzida pela referência ao nó borromeano, como modelo para se pensar a clínica, seria a possibilidade de apresentar uma superação da formalização do complexo de Édipo. Superação que Lacan chamou de um além-do-Édipo e que incluiria transcender a forma anedótica considerada no modelo estrutural.

No Seminário RSI, Lacan (1975) aponta que Freud identificou os registros R, $\mathrm{S}$, e I, porém teria amontoado-os e não os relacionado entre si. Lacan afirma o seu 


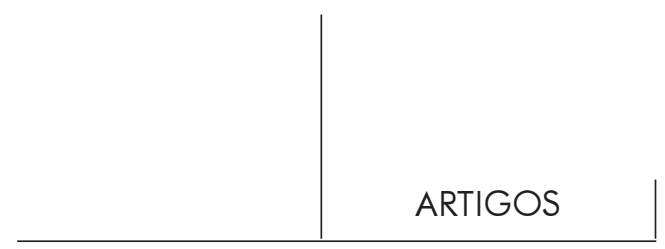

avanço em relação a Freud ao articular estes registros entre si, fazendo-o a partir das propriedades da figura topológica do nó borromeano.

Isto o leva a considerar que os registros se equivalem e que, por isso, só poderiam ser diferenciados por um quarto nó que nomearia os três registros. Então, é através desse quarto nó que seria estabelecida uma relação entre os três registros - do R, do S e do I. Este quarto nó Lacan chamou-o, sucessivamente, de Realidade psíquica, complexo de Édipo, Função Paterna e Sinthome.

Para Lacan, a função paterna é o que assegura a função do nó. Por isso, no modelo borromeano, a função paterna foi referida como Père-Version.

A clínica borromeana consiste em identificar, a partir do envoltório formal do sintoma, a possível existência de um lapso no nó; o que aconteceria pela ausência da amarração adequada dos registros pelo quarto nó que caracteriza a função paterna.

Lacan (1976), a partir do exame da obra de Joyce, afirmou que tal escritor seria um caso de psicose não desencadeada. Com este exemplo, Lacan mostrou a possibilidade de haver uma suplência da função paterna que teria falhado no caso de Joyce. Falha que teria impedido o correto enlaçamento do registro do I com o registro do $\mathrm{S}$, com a conseqüente produção de um lapso do nó que, segundo Lacan, justificaria entender-se a obra de Joyce como seu sintoma.

Nesta outra maneira de pensar a clínica existem diferenciações, mas não existe uma oposição de um sim ou de um não para a função paterna, o que ocorre na clínica estruturalista.

Então, se a primeira clínica de Lacan foi chamada de estruturalista, descontinuista e categorial, em contrapartida, esta outra clínica seria elástica, gradual e não-classificatória.

Esta segunda clínica é uma forma de fazer equivaler o Sinthome ao Nomedo-pai.

À guisa de exemplo deste outro modelo de clínica, pode-se citar os diagnósticos feitos por Lacan nas apresentações de pacientes. Diagnósticos, estes, que podemos chamar de diagnósticos lacanianos e que seriam formulados em referência ao modelo do nó borromeano e não mais em referência à relação do Sujeito com o Outro, como acontecia na clínica estrutural.

Um destes diagnósticos seria o que Lacan chamou de doenças da mentalida$d e$, que seria um diagnóstico que se sustentaria no entendimento dos sintomas do sujeito como efeito de uma emancipação da relação imaginária, ou seja, como consequiência do sujeito não estar submetido aos efeitos do simbólico.

Para Lacan, estar submetido à escansão simbólica é o destino de todo ser falante. Por isto, todo falante estaria sempre afetado por uma mentalidade, o que quer dizer que todo falante tem representações condicionadas pela linguagem. 


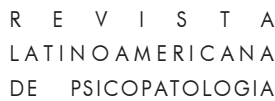

Quando Lacan se referiu à sua paciente como enferma da mentalidade queria dizer que, para esta paciente, nenhum objeto tinha importância, nenhum objeto captava sua libido ou que ela não podia representá-lo.

Outro exemplo de diagnóstico lacaniano foi o diagnóstico de psicose lacania$n a$. Este exemplo é uma referência ao caso que Lacan evocou no seminário sobre Joyce, onde um paciente que havia lido os Escritos, apresentava o que ele mesmo chamava de palavras impostas, nas quais não se reconhecia como enunciador.

Cada uma dessas palavras impostas exigia deste sujeito que ele a completasse com uma frase da qual ele não sabia ser o emissor. Assim, este sujeito assistia ao surgimento do discurso do Outro de uma forma direta.

Dentro do referencial da clínica borromeana, pode-se entender estes fenômenos como efeito do próprio sujeito isolar o $\mathrm{R}$ do $\mathrm{S}$ e esses do I.

A evolução do ensino de Lacan, e o uso que ele fez das categorias diagnósticas, evidencia o uso do diagnóstico como produto de uma combinatória de signos. Por sua vez, a combinatória de signos que determina um diagnóstico é efeito do referencial teórico em uso.

Daí que as categorias diagnósticas só podem ser entendidas como convenções de caráter pragmático, só podem ser entendidas como efeitos do que se chamou de razão classificatória.

\section{Referências bibliográficas}

ClassificaÇão Internacional das Doenças, 10 a versão. Porto Alegre: Artes Médicas, 1998. Dalgalarrondo, P. Psicopatologia e semiologia dos transtornos mentais. Porto Alegre: Artes Médicas, 2000.

FÉDIDA, P. De uma psicopatologia fundamental - Nota sobre a noção de paradigma. Revista Latinoamericana de Psicopatologia Fundamental, vol. I, n. 3, set.1998.

e Lacoste, P. Psicopatologia/Metapsicologia - A função dos pontos de vista. Revista Latinoamericana de Psicopatologia Fundamental, vol. I, n. 2, jun.1998.

LACAN, J. O seminário. Livro XXII. RSI. Ornicar?, n. 3, 1975.

O seminário. Livro XIII. Le sinthome. Ornicar?, n. 7, 1976.

De nossos antecedentes. In Escritos. Rio de Janeiro: Jorge Zahar, 1998.

Introdução à edição alemã de um primeiro volume dos escritos. Falo - Rev. Brasileira do Campo Freudiano, ano II, n. 2, jan./jul.1998a.

MILleR, J.-A. Os casos raros, inclassificáveis, da clínica psicanalítica - Conversação de Arcachon. São Paulo: s/editora, 1998.

SAuRí, J. Que es diagnosticar en psiquiatría. Buenos Aires: Bonum, 1994. Em português: $O$ que é diagnosticar em psiquiatria. São Paulo: Escuta, 2001. 


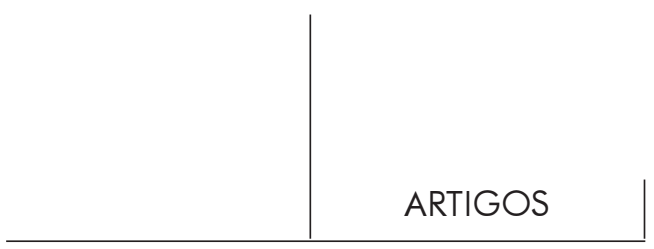

Resumo

Para abordar la cuestión del diagnóstico en psicopatologia en la psicoanálisis de orientación lacaniana, el autor primero cuestiona la existencia de una psicopatologia psicoanalitica, así como la existencia de una especificidad para el diagnóstico psicoanalítico.

Desenvolve después la noción de envoltorio formal del síntoma y de posición subjetiva como los ejes que orientan el diagnóstico en la psicoanálisis lacaniana.

Desde ahí el autor apunta la existencia de dos modelos clínicos en Lacan, que impone dos modelos diagnósticos: un primer, la clínica estrutural, y un según, la clínica borromeana.

La clínica estrutural seria descontinuista y categorial y estaria fundada sobre la modalidad de la oposición orientandose en función de la oposición de la existencia y non de la función partena. Esa clínica es tripartida entre neurosis, psicosis y perversión.

La clínica borromeana tiene la característica de no referirse a las categorias nosológicas de la psiquiatría clasica y se funda en la relación de los registros del Imaginário, del Simbólico y del Real, según las propiedades de la figura topologica del nudo Borromeano. Ella es una clínica continuista y no categorial.

Palabras llave: Diagnóstico, psicopatología, clínica estrutural, clínica borromeana

Pour aborder la question du diagnostique en psychopatologie dans la psychanalyse d'orientation lacaniene, l'auteur demande en premier l'existence d'une psychopatologie psychanalitique, tel que l'existence dúne especificité pour le diagnostique psychanalitique.

Développe après la notion d'enveloppe formel du symptôme et de la position subjectif comme les axes qui orientent le diagnostique dans la psychanalise lacaniene.

Dés là l'auteur pointe l'existence de deux modèles cliniques chez Lacan, ce qu'impose deux modèles diagnostiques: un premier, la clinique structurel, et un deusième, la clinique borromeène.

La clinique structurel aura été descontinuiste et categoriel et fondée sur la modalité d'oposition en s'orientant en fonction d'oposition de l'existence et non existence de la fonction paterne. Cet clinique est tripartite entre névrose, psychose et perversion.

La clinique borromeène a la caracteristique de non se référer a les catégories nosologiques de la psychiatrie classique et se fonde dans la relation des registres d'Imaginaire, du Symbolique et du Réel, second les propriétes de figure topologique du noeud Borromeéne. Elle est une clinique continuiste et non categoriel.

Mots clés: Diagnostique, psychopatologie, clinique structurel, clinique borroneéne

To approach the question of psychopathological diagnosis in psychoanalysis of Lacanian orientation, the author first questions the existence of a psychoanalytical 


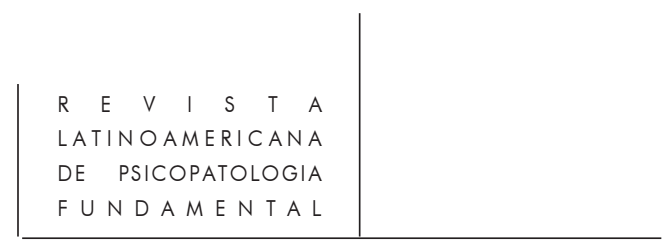

psychopathology, in fact, the existence of any specificity in psychoanalytic diagnosis.

He then goes into the notion of formal encasing of symptoms and of the subjective position as the central themes that orient diagnosis in Lacanian psychoanalysis.

The author holds that there are two clinical models in Lacan, and this fact requires two models of diagnosis, the structural clinical model and the Borromenean clinical model.

The structural clinical model is non-continuous and categorical, based on the modality of opposition and oriented in function of the opposition between the existence and non-existence of the father function. This type of clinical approach is tripartite, dealing with neurosis, psychosis and perversion.

The Borromenean clinic has the characteristic of making no reference to the nosological categories of classical psychiatry. It is based on the relationship among the registers of the Imaginary, the Symbolic and the Real, according to the properties of the topological figure of the Borromenean knot. It is a continuist rather than categorical clinic.

Key words: Diagnosis, psychopathology, structural clinic, Borromenean clinic

Versão inicial recebida em dezembro de 2000

Versão revisada recebida em abril de 2001 